DOI: $10.4274 /$ gulhane.galenos.2020.1047

Gulhane Med J 2021;63:13-19

\title{
Assessment of mandibular buccal shelf for an ideal miniscrew implantation site using cone-beam computed Tomography
}

\author{
(1) Murali Patla ${ }^{1}$, (1) Vartika Kumari ${ }^{2}$, (1) Ravi Subrahmanya ${ }^{1}$, (1) Crystal Runa Soans ${ }^{1}$, (1) Sonika Achalli ${ }^{3}$
}

${ }^{1}$ Nitte (Deemed to be University), AB Shetty Memorial Institute of Dental Sciences (ABSMIDS), Department of Orthodontics, Mangalore, India

${ }^{2}$ Ridgetop Dental International, Bangalore, India

${ }^{3}$ Nitte (Deemed to be University), AB Shetty Memorial Institute of Dental Sciences (ABSMIDS), Department of Oral Medicine and Radiology, Mangalore, India

\section{Date submitted:}

25.03.2020

Date accepted:

10.08.2020

Online publication date:

15.03.2021

\section{Corresponding Author:}

Dr. Sonika Achalli BDS, MDS, Nitte

(Deemed to be University), AB Shetty

Memorial Institute of Dental Sciences

(ABSMIDS), Department of Oral

Medicine and Radiology, Mangalore, India

drachallisonika@nitte.edu.in

ORCID:

orcid.org/0000-0002-7203-8214

Keywords: Miniscrew implant, cortical bone thickness, buccal shelf area

\begin{abstract}
Aims: The aim of the study was to evaluate the cortical bone thickness and bone width of the buccal shelf area and to determine the optimal sites for mini screw-implant placement.

Methods: In this retrospective study, cortical bone thickness and buccal shelf bone width of 20 patients were measured at 3 sites on both right and left sides using cone-beam computed tomography images. The three sites were the measurements were done were areas buccal to the distobuccal cusps of mandibular first molar (6D), and buccal to the mesiobuccal (7M) and distobuccal (7D) cusps of mandibular second molar. Also, buccal shelf bone width was measured at 8 and $4 \mathrm{~mm}$ from the cementoenamel junction (CEJ).

Results: The study group included 10 males with the mean age of 24.5 years and 10 females with the mean age of 26.5 years. There was statistically significant difference between the cortical bone thickness, between the left and the right sides in the mesiobuccal cusp of mandibular $2^{\text {nd }}$ molar (MB7) and the distobuccal cusp of mandibular $2^{\text {nd }}$ molar (DB7). The values obtained at MB7 on the right and left sides were $4.74 \pm 0.94$ and $4.16 \pm 0.91$ with $p$ value of 0.006 , respectively. Similarly, data obtained at DB7 on the right and left sides were $4.13 \pm 0.94$ and $5.08 \pm 1.12$ with $p$ value of $15<0.001$, respectively.
\end{abstract}

Conclusions: Maximum bone thickness was found at distal region of the mandibular second molar at $8 \mathrm{~mm}$ from the CEJ, hence this is the ideal site for miniscrew placement in buccal shelf area (horizontal bone level at $\mathrm{DB} 7=6.01 \mathrm{~mm}$ and vertical bone level at $\mathrm{DB} 7=4.06 \mathrm{~mm}$ ).

\section{Introduction}

The introduction of absolute anchorage in orthodontics has changed the way we see treatment planning of an orthodontic case. It has increased the envelope of tooth movement by fixed orthodontic appliances. The position of these miniscrews is based on the mechanical requirement for a particular case (14). The most commonly used sites are the maxillary alveolar process, retromolar area, palate, mandibular and maxillary buccal alveolar processes (2-6).

Thickness of the cortical bone is an important factor to be considered for the stability of miniscrew implant. Inadequate bone thickness leads to diminished primary stability of the miniscrew, which will later lead to its failure during the orthodontic treatment. Less than $1 \mathrm{~mm}$ cortical bone thickness can lead to higher rate of failure as compared to $1 \mathrm{~mm}$ or more.

Cortical bone with thickness of less than $1 \mathrm{~mm}$ is vulnerable to stresses, which further causes bone loss in the nearby area (7-14). The two most important factors for the initial stability of the miniscrew are the quantity and quality of bone. These two factors also have the effect on the long term stability. Stationary anchorage failure occurs mostly due to diminished bone density and the

${ }^{\odot}$ Copyright 2021 by the University of Health Sciences Turkey, Gülhane Faculty of Medicine / Gülhane Medical Journal published by Galenos Publishing House. 
incidences further increase in case of reduced cortical bone thickness (7-14). The thickness of the bone can be studied with the help of cone-beam computed tomography (CBCT). Hence, it is better to use CBCT in bone screw cases rather than panoramic radiograph and lateral cephologram as it fails to provide full information about the subject.

Recently, the introduction of bone screws in orthodontics has made full arch distalization and camouflage treatment easier. The buccal shelf area is a site for the placement of such a bone screw for the treatment of class 3 cases (15-18). Despite several CBCT studies, there is inconsistency in the placement site of these implants. Varied bone thickness in these areas has made the standardization difficult as the bone width and thickness change every millimeter. As we go away from the alveolar crestal region, the bone thickness and density increase.

Importance should also be given to the soft tissue and nerve relation with roots of teeth in the neighboring areas (19).

The purpose behind the study was to evaluate the thickness of the cortical bone and bone width of the buccal shelf area and thus to determine the ideal sites for the placement of miniscrew implant in the buccal shelf area of the mandible using CBCT.

\section{Methods}

This retrospective study included full field of view (FOV) CBCT records of 20 patients in the age group of 19 to 33 years, including 10 males and 10 females who were admitted to the department of Orthodontics for orthodontic treatment. Full FOV CBCT images were taken for evaluating impacted canines, for assessing sites for zygomatic implants and for the purpose of orthognathic surgeries. Informed consent was also taken from all subjects. Ethical clearance for the study was obtained from $A B$ Shetty Memorial Institute of Dental Sciences Institutional Ethical Committee (Cert. no. ABSM/EC02/2016). The information for each image analyzed was retrieved from the records maintained at the department of oral radiology at the institute. Subjects who had full complement of teeth except for third molars with class 1 molar relation were included in the study. Subjects who had severe skeletal abnormalities and facial anomalies, periodontal disease, systemic illness and endocrinal disorders were not included in the study. The records were analyzed by a single observer.

The CBCT images were taken using Planmeca ProMax ${ }^{\mathrm{TM}}$ Machine (230-240 V, $50 \mathrm{~Hz}, 16 \mathrm{~A}$ ) manufactured by PLANMECA OY (Helsinki Finland). Full FOV images were retrieved from already existing CBCT images. The images were analyzed using Planmeca Romexis Viewer (version 4.1.2). $2 \mathrm{~mm}$ cross sections of the mandible were obtained. The 3D images were reconstructed around the axial plane. These measurements were made from $4 \mathrm{~mm}$ and $8 \mathrm{~mm}$ from the cementoenamel junction (CEJ). The CEJ was customized by tracing the CEJ of each tooth individually on the coronal view.
Thickness of the cortical bone and the width of the buccal shelf bone were measured at 3 sites on both right and left sides. Measurements were done at areas buccal to the distobuccal cusps of mandibular first molar (6D), and buccal to the mesiobuccal (7M) and distobuccal (7D) cusps of mandibular second molar. Cortical bone thickness was measured (parallel to buccal root surface) from the midpoint of the osseous ledge buccal to first and second mandibular molars (buccal shelf area) (Figure 1).
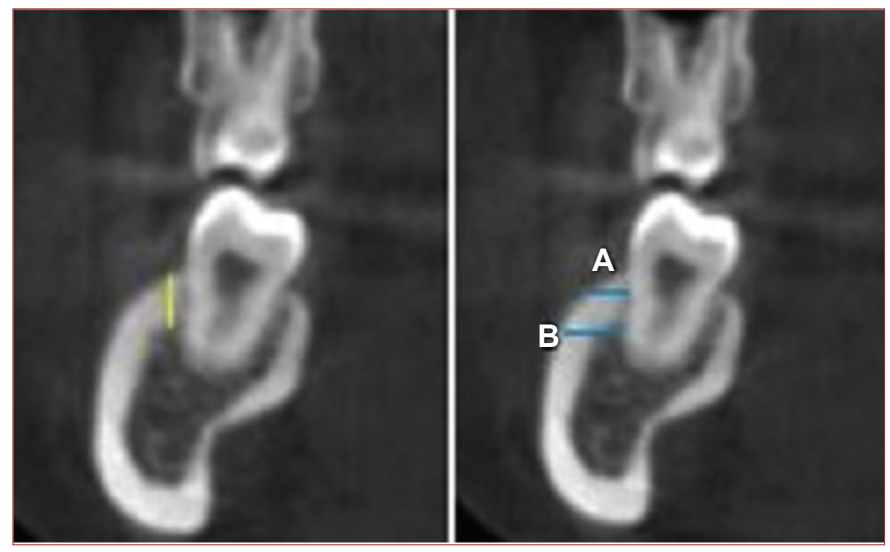

Figure 1. Measurement of horizontal and vertical cortical bone thickness

Buccal shelf bone width was the total bone width present in buccolingual direction (parallel to occlusal plane) from the root of the mandibular molars to the most buccal point of the alveolar bone at 8 and $4 \mathrm{~mm}$ from the CEJ. These measurements were recorded at 3 sites at $4 \mathrm{~mm}$ and $8 \mathrm{~mm}$ : buccal to the distobuccal cusp of mandibular first molar (6D4, 6D8), and buccal to the mesiobuccal (7M4, 7M8) and distobuccal (7D4, 7D8) cusps of mandibular second molar (Figure 1).

All measurements were made on the reconstructed axial plane using the "Measure Length" Tool. (Planmeca Romexis V. 4.1.2 $\left.{ }^{\mathrm{TM}}\right)$.

\section{Statistical Analysis}

The data collected were entered in Microsoft Excel work sheet and analyzed using IBM SPSS version 22. The descriptive statistics were represented in the form of mean and standard deviation.

A paired Student's t-test was used for additional preliminary data analysis to test the differences between the left and right sides in the cortical bone width. Analysis of variance was used to evaluate the importance of the site and measurement level on cortical bone thickness and buccal shelf bone width. The posthoc Tukey test was used to further evaluate interactions of the different variables. Intraclass correlation was also evaluated.

\section{Results}

This retrospective study included 20 patients comprising of 10 males with the mean age of 24.5 years and 10 females with 
the mean age of 26.5 years (Table 1 ). The horizontal and vertical bone levels between right and left sides at different sites were compared (Table 2) and there was no statistically significant difference between the left and the right sides of the cortical bone width at 4 and $8 \mathrm{~mm}$ from CEJ. There was statistically significant difference between the cortical bone thickness between the left and the right sides in MB7 and DB7. The values obtained at MB7 on the right and left sides were $4.74 \pm 0.94$ and $4.16 \pm 0.91$ with $p$ value of 0.006 , respectively. Similarly, data obtained at DB7 on the right and left sides were $4.13 \pm 0.94$ and $5.08 \pm 1.12$ with $p$ value of $101<0.001$, respectively.

The horizontal bone levels (cortical bone width) between different sites at $4 \mathrm{~mm}$ were compared (Tables 3, 4) and statistically significant difference was found among DB6, MB7 and DB7.

The maximum bone width was seen at DB7 (with average thickness of $4.79 \mathrm{~mm})$ followed by MB7 $(3.80 \mathrm{~mm})$ and minimum levels at DB6 $(1.81 \mathrm{~mm})$.

\begin{tabular}{lll|}
\hline \multicolumn{3}{l}{ Table 1. Basic data of participants } \\
\hline Gender & Number & Mean age (years) \\
\hline Males & 10 & 24.5 \\
\hline Females & 10 & 26.5 \\
\hline
\end{tabular}

It was also seen that when the horizontal bone levels between different sites at $8 \mathrm{~mm}$ (Tables 3, 4) were compared, there was statistically significant difference among the DB6, MB7 and DB7. The maximum bone width was seen at DB7 (with average thickness of $6.01 \mathrm{~mm})$ followed by MB7 $(4.85 \mathrm{~mm})$ and minimum levels at DB6 $(2.27 \mathrm{~mm})$.

The vertical bone levels between different sites (Tables 3, 4) were also compared and statistically significant difference was found among the DB6, MB7 and DB7. The maximum bone width was seen at DB7 (with average thickness of $4.60 \mathrm{~mm}$ ) followed by MB7 (4.45 mm) and minimum levels at DB6 (3.42 $\mathrm{mm})$. Intraclass correlation was also evaluated for horizontal and vertical bone levels at different sites (Tables 5, 6).

\section{Discussion}

The decision for placing the miniscrew is dependent on the bio-mechanics and the local anatomy of that particular region. Local anatomy varies with different individuals, but some sites are more reliable and show more bone thickness than others $(1,5,20)$. The two most important factors for the primary stability of the implant are the quality and quantity of bone. CBCT may be used to study this, though the gold standard for studying the quality of bone is biopsy.

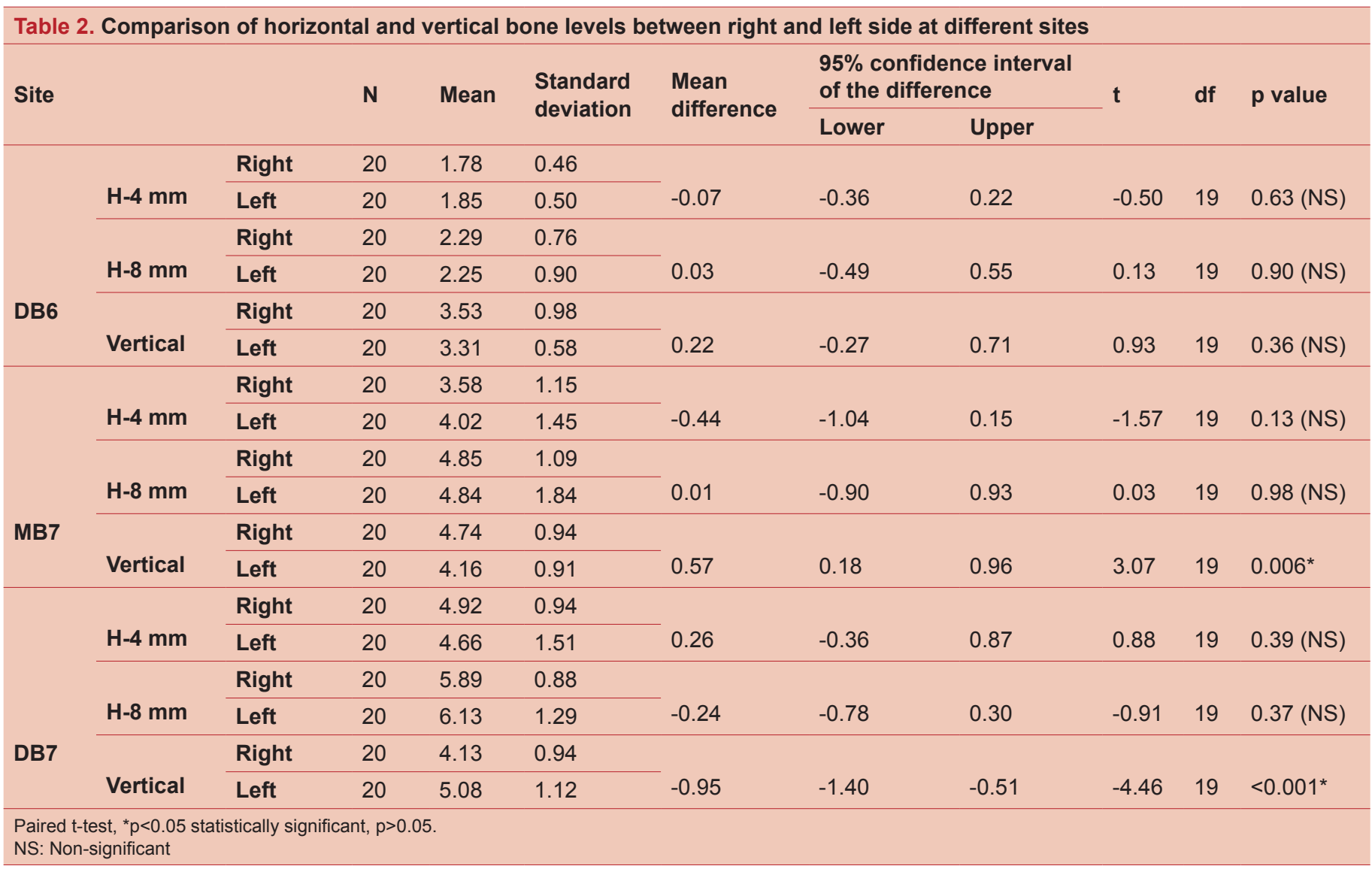




\begin{tabular}{|c|c|c|c|c|c|c|}
\hline \multirow{2}{*}{$4 \mathrm{~mm}$} & \multirow{2}{*}{ Sites } & \multirow{2}{*}{$\mathbf{N}$} & \multirow{2}{*}{ Mean } & \multirow{2}{*}{ Standard deviation } & \multicolumn{2}{|l|}{ ANOVA } \\
\hline & & & & & $\mathbf{F}$ & $p$ value \\
\hline \multirow{3}{*}{ Right } & DB6 & 20 & 1.78 & 0.46 & \multirow{3}{*}{61.82} & \multirow{3}{*}{$<0.001^{*}$} \\
\hline & MB7 & 20 & 3.58 & 1.15 & & \\
\hline & DB7 & 20 & 4.92 & 0.94 & & \\
\hline \multirow{3}{*}{ Left } & DB6 & 20 & 1.85 & 0.50 & \multirow{3}{*}{28.32} & \multirow{3}{*}{$<0.001^{*}$} \\
\hline & MB7 & 20 & 4.02 & 1.45 & & \\
\hline & DB7 & 20 & 4.66 & 1.51 & & \\
\hline \multirow{3}{*}{ Average } & DB6 & 20 & 1.81 & 0.36 & \multirow{3}{*}{53.37} & \multirow{3}{*}{$<0.001^{*}$} \\
\hline & MB7 & 20 & 3.80 & 1.14 & & \\
\hline & DB7 & 20 & 4.79 & 1.07 & & \\
\hline \multirow{2}{*}{$8 \mathrm{~mm}$} & \multirow{2}{*}{ Sites } & \multirow{2}{*}{$\mathbf{N}$} & \multirow{2}{*}{ Mean } & \multirow{2}{*}{ Standard deviation } & \multicolumn{2}{|c|}{ ANOVA } \\
\hline & & & & & $F$ & $p$ value \\
\hline \multirow{3}{*}{ Right } & DB6 & 20 & 2.29 & 0.76 & \multirow{3}{*}{81.35} & \multirow{3}{*}{$<0.001^{*}$} \\
\hline & MB7 & 20 & 4.85 & 1.09 & & \\
\hline & DB7 & 20 & 5.89 & 0.88 & & \\
\hline \multirow{3}{*}{ Left } & DB6 & 20 & 2.25 & 0.90 & \multirow{3}{*}{39.98} & \multirow{3}{*}{$<0.001^{*}$} \\
\hline & MB7 & 20 & 4.84 & 1.84 & & \\
\hline & DB7 & 20 & 6.13 & 1.29 & & \\
\hline \multirow{3}{*}{ Average } & DB6 & 20 & 2.27 & 0.62 & \multirow{3}{*}{84.62} & \\
\hline & MB7 & 20 & 4.85 & 1.16 & & $<0.001^{*}$ \\
\hline & DB7 & 20 & 6.01 & 0.94 & & \\
\hline & & & & & ANOVA & \\
\hline Vertical & Sites & $\mathbf{N}$ & Mean & Standard deviation & $F$ & $p$ value \\
\hline & DB6 & 20 & 3.53 & 0.98 & & \\
\hline Right & MB7 & 20 & 4.74 & 0.94 & 797 & ค००० * \\
\hline & DB7 & 20 & 4.13 & 0.94 & & 0.001 \\
\hline & DB6 & 20 & 3.31 & 0.58 & & \\
\hline Left & MB7 & 20 & 4.16 & 0.91 & 19.44 & $<0.001^{*}$ \\
\hline & DB7 & 20 & 5.08 & 1.12 & & \\
\hline & DB6 & 20 & 3.42 & 0.61 & & \\
\hline Average & MB7 & 20 & 4.45 & 0.83 & 13.10 & $<0.001^{*}$ \\
\hline & DB7 & 20 & 4.60 & 0.91 & & \\
\hline
\end{tabular}

Mandibular buccal shelf area is the area between the buccal frenum and anterior border of masseter muscle. It extends medially from the crest of the ridge, laterally to the external oblique ridge and distally up to the retromolar pad. There is significant amount of bone present in this area and thus permits clinicians to place miniscrews in a direction parallel to the long axes of the molar roots. With this mode of insertion, screw-toroot contact can be avoided during the procedure of insertion and also during retraction of the posterior tooth (21). Buccal shelf area is one of the areas which are most favorable insertion sites for the placement of miniscrew especially in class 3 cases.
The purpose of this study was to investigate the cortical bone thickness and cortical bone width at 3 sites (DB6 MD7 DB7) and two levels $(4 \mathrm{~mm}$ and $8 \mathrm{~mm}$ ) from the CEJ using CBCT technology in Indian population.

The findings of this study show different bone thickness and bone width in different region of buccal shelf area. The width of bone increased from the first molar region to the second molar region, which was statistically significant $(p=0.006)$. The minimum bone width was measured with respect to first molar region (at $4 \mathrm{~mm}$ site $=1.86 \mathrm{~mm}$ and at $8 \mathrm{~mm}$ site $=2.27 \mathrm{~mm}$ ), hence it is not suitable for miniscrew placement. The maximum 


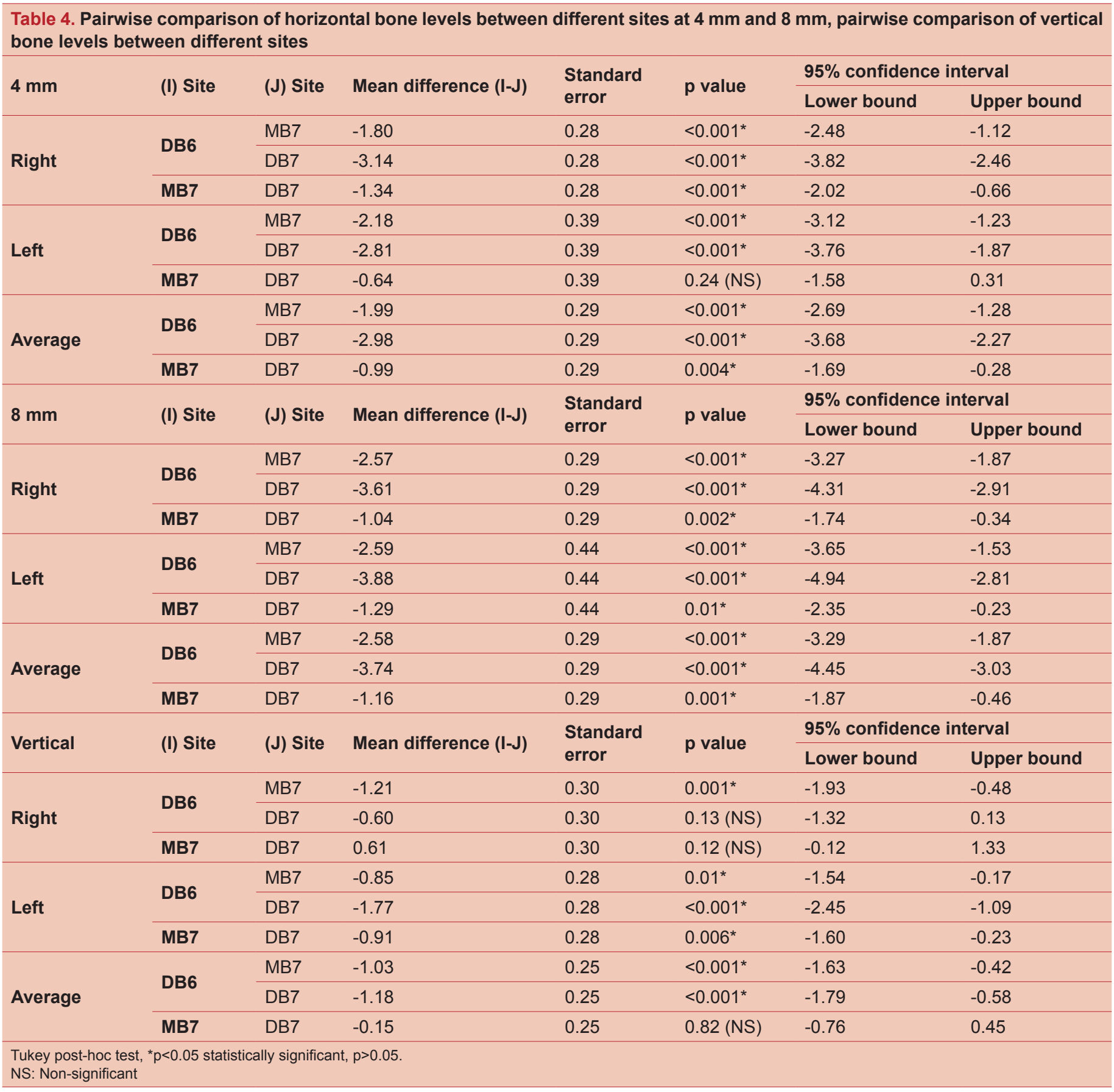

width of bone was witnessed with respect to distobuccal cusp of second molar (at $4 \mathrm{~mm}$ site $=4.79 \mathrm{~mm}$ and at $8 \mathrm{~mm}$ site $=6.01$ $\mathrm{mm}$ ) hence it is the best region for the placement of miniscrew.

There was variation in the width of bone seen from $4 \mathrm{~mm}$ from CEJ to $8 \mathrm{~mm}$ from CEJ. The width of the bone was more on the $8 \mathrm{~mm}$ site compared to $4 \mathrm{~mm}$ site. The result of the bone width was in correlation with the studies performed by Elshebiny et al. (19) and Nucera et al (22). Bone thickness is one of the essential factors for primary stability of miniscrew and it correlates directly to the placement torque, which in turn influences the stability of the screw. Baumgaertel $(23,24)$ confirmed the importance of cortical bone thickness in implant site preparation. Lim et al. (25) also mentioned the significant role of cortical bone thickness in the evaluation of maximum insertion torque value as it determines the stability of the implant. Various studies have proven that extreme values of cortical bone thickness can affect the insertion outcome. Areas of very thin bone will lead to stress in the bone and later lead to implant failure whereas very thick bone will have good initial stability but later will lead to implant failure due to compression of the bone. In case where there is excessive bone thickness, predrilling is recommended as it will produce lesser heat at the implant bone surface. The thickness 


\begin{tabular}{|c|c|c|c|c|c|}
\hline \multirow{2}{*}{ Tooth } & \multirow{2}{*}{$\mathrm{mm}$} & \multirow{2}{*}{ Side } & \multirow{2}{*}{$\begin{array}{l}\text { Intraclass } \\
\text { correlation }\end{array}$} & \multicolumn{2}{|c|}{$\begin{array}{l}95 \% \text { confidence } \\
\text { interval }\end{array}$} \\
\hline & & & & $\begin{array}{l}\text { Lower } \\
\text { bound }\end{array}$ & $\begin{array}{l}\text { Upper } \\
\text { bound }\end{array}$ \\
\hline \multirow{4}{*}{ DB6 } & \multirow{2}{*}{4} & Left & 0.99 & 0.99 & 1.00 \\
\hline & & Right & 0.99 & 0.99 & 1.00 \\
\hline & \multirow{2}{*}{8} & Left & 1.00 & 0.99 & 1.00 \\
\hline & & Right & 1.00 & 0.99 & 1.00 \\
\hline \multirow{4}{*}{ MB7 } & \multirow{2}{*}{4} & Left & 1.00 & 1.00 & 1.00 \\
\hline & & Right & 1.00 & 0.99 & 1.00 \\
\hline & \multirow{2}{*}{8} & Left & 1.00 & 1.00 & 1.00 \\
\hline & & Right & 1.00 & 1.00 & 1.00 \\
\hline \multirow{4}{*}{ DB7 } & \multirow{2}{*}{4} & Left & 1.00 & 1.00 & 1.00 \\
\hline & & Right & 1.00 & 0.99 & 1.00 \\
\hline & \multirow{2}{*}{8} & Left & 1.00 & 1.00 & 1.00 \\
\hline & & Right & 1.00 & 0.99 & 1.00 \\
\hline \multirow{2}{*}{ Tooth } & \multirow{2}{*}{$\mathrm{mm}$} & \multirow{2}{*}{\multicolumn{2}{|c|}{$\begin{array}{l}\text { Intraclass correlation } \\
\text { Lower bound }\end{array}$}} & \multicolumn{2}{|c|}{$\begin{array}{l}95 \% \text { confidence } \\
\text { interval }\end{array}$} \\
\hline & & & & \multicolumn{2}{|l|}{$\begin{array}{l}\text { Upper } \\
\text { bound }\end{array}$} \\
\hline \multirow{2}{*}{ DB6 } & 4 & 0.99 & & 0.99 & 1.00 \\
\hline & 8 & 1.00 & & 0.99 & 1.00 \\
\hline \multirow{2}{*}{ MB7 } & 4 & 1.00 & & 1.00 & 1.00 \\
\hline & 8 & 1.00 & & 1.00 & 1.00 \\
\hline \multirow{2}{*}{ DB7 } & 4 & 1.00 & & 1.00 & 1.00 \\
\hline & 8 & 1.00 & & 1.00 & 1.00 \\
\hline
\end{tabular}

\begin{tabular}{|c|c|c|c|c|c|}
\hline \multirow{2}{*}{ Tooth } & \multirow{2}{*}{$\mathrm{mm}$} & \multirow{2}{*}{ Side } & \multirow{2}{*}{$\begin{array}{l}\text { Intraclass } \\
\text { correlation }\end{array}$} & \multicolumn{2}{|c|}{$\begin{array}{l}95 \% \text { confidence } \\
\text { interval }\end{array}$} \\
\hline & & & & Lower bound & $\begin{array}{l}\text { Upper } \\
\text { bound }\end{array}$ \\
\hline \multirow{2}{*}{ DB6 } & \multirow{2}{*}{4} & Left & 0.99 & 0.99 & 1.00 \\
\hline & & Right & 1.00 & 0.99 & 1.00 \\
\hline \multirow{2}{*}{ MB7 } & \multirow{2}{*}{4} & Left & 1.00 & 0.99 & 1.00 \\
\hline & & Right & 1.00 & 1.00 & 1.00 \\
\hline \multirow{2}{*}{ DB7 } & \multirow{2}{*}{4} & Left & 1.00 & 0.99 & 1.00 \\
\hline & & Right & 1.00 & 0.99 & 1.00 \\
\hline \multirow[t]{2}{*}{ Tooth } & \multirow[t]{2}{*}{$\mathrm{mm}$} & \multirow{2}{*}{\multicolumn{2}{|c|}{$\begin{array}{l}\text { Intraclass } \\
\text { correlation } \\
\text { Lower bound }\end{array}$}} & \multicolumn{2}{|c|}{$\begin{array}{l}95 \% \text { confidence } \\
\text { interval }\end{array}$} \\
\hline & & & & \multicolumn{2}{|l|}{ Upper bound } \\
\hline DB6 & 4 & 1.00 & & 0.99 & 1.00 \\
\hline MB7 & 4 & 1.00 & & 1.00 & 1.00 \\
\hline DB7 & 4 & 1.00 & & 1.00 & 1.00 \\
\hline
\end{tabular}

of the bone increases from mesial site to the distal as shown by other studies as well. The maximum thickness was found with respect to the distobuccal cusp of the second molar and there was a statistically significant difference among the three sites. It was in accordance with studies done by Elshebiny et al. (19) and Nucera et al. (22). The torque values used in the buccal shelf area is generally higher than other areas as the cortical bone thickness is more, but care should be taken not to exceed the recommended torque levels as it might fracture the implant. In case of excessive bone thickness, drilling should be done and then the implant should be placed.

The cortical bone thickness in the present retrospective study was done on full FOV rather than small FOV, which could provide a better image quality and smaller voxel size.

Ethnicity does play a role in the morphology of bone as the values found in this study were different from the values found in the study done by Elshebiny et al. (19) and Nucera et al. (22). This might be dependent on the facial type of patients and the skeletal malocclusion of the patient. Also, comparison of cortical bone thickness between adults and adolescent groups can be studied. Hence, it is recommended that further research in this area will give a better picture of the bone in the buccal shelf region.

\section{Conclusion}

The mandibular buccal shelf area is a suitable site for bone screw placement. With the limitation of the study, the bone buccal to the mandibular second molar region appears to be the most favorable site for the miniscrew placement. The maximum bone thickness was found at distal region of the mandibular second molar at $8 \mathrm{~mm}$ from the CEJ, hence this is the ideal site for miniscrew placement. The insertion of the miniscrew at the first molar region would require further investigation.

\section{Acknowledgements}

The authors acknowledge the support of the principal of the institution during the period of the study. The authors also thank the statistician for helping with the statistics. The authors also acknowledge the contributions made by the department of Oral Medicine and Radiology regarding $\mathrm{CBCT}$ imaging.

\section{Ethics}

Ethics Committee Approval: Ethical clearance for the study was obtained from AB Shetty Memorial Institute of Dental Sciences Institutional Ethical Committee (Cert. no. ABSM/ EC02/2016).

Informed Consent: Retrospective study.

Peer-review: Externally peer-reviewed.

\section{Authorship Contributions}

Surgical and Medical Practices: V.K., Concept: M.P., Design: M.P., Data Collection or Processing: V.K., Analysis or Interpretation: R.S., C.R.S., S.A., Literature Search: V.K., R.S., C.R.S., S.A., Writing: V.K., S.A. 
Conflict of Interest: No conflict of interest was declared by the authors.

Financial Disclosure: The authors declared that this study received no financial support.

\section{References}

1. Baumgaertel S, Hans MG. Buccal cortical bone thickness for mini-implant placement. Am J Orthod Dentofacial Orthop. 2009;136:230-235.

2. Park HS, Kwon OW, Sung JH. Nonextraction treatment of an open bite with microscrew implants anchorage. Am J Orthod Dentofacial Orthop. 2006;130:391-402.

3. Roth A, Yildirim M, Diedrich $P$. Forced eruption with microscrew anchorage for preprosthetic leveling of the gingival margin. J Orofac Orthop. 2004;65:513-519.

4. Park YC, Choi YJ, Choi NC, Lee JS. Esthetic segmental retraction of maxillary anterior teeth with a palatal appliance and orthodontic mini-implants. Am J Orthod Dentofacial Orthop. 2007;131:537-544.

5. Baumgaertel S. Quantitative investigation of palatal bone width and cortical bone thickness for mini-implant placement in adults. Am J Orthod Dentofacial Orthop. 2009;136:104-108.

6. Xun C, Zeng X, Wang X. Microscrew anchorage in skeletal anterior open-bite treatment. Angle Orthod. 2007;77:47-56.

7. Schätzle M, Golland D, Roos M, Stawarczyk B. Accuracy of mechanical torque-limiting gauges for mini-screw placement. Clin Oral Implants Res. 2010;21:781-788.

8. Motoyoshi M, Yoshida T, Ono A, Shimizu N. Effect of cortical bone thickness and implant placement torque on stability of orthodontic mini-implants. Int J Oral Maxillofac Implants. 2007;22:779-784.

9. Motoyoshi M, Inaba M, Ono A, Ueno S, Shimizu N. The effect of cortical bone thickness on the stability of orthodontic miniimplants and on the stress distribution in surrounding bone. Int J Oral Maxillofac Surg. 2009;38:1318.

10. Stahl E, Keilig L, Abdelgader I, Jager A, Bourauel C. Numerical analyses of biomechanical behavior of various orthodontic anchorage implants. J Orofac Orthop. 2009;70:115-127.

11. Motoyoshi M, Ueno S, Okazaki K, Shimizu N. Bone stress for a mini-implant close to the roots of adjacent teeth 3D finite element analysis. Int J Oral Maxillofac Surg. 2009;38:363-368.

12. Kravitz ND, Kusnoto B. Risks and complications of orthodontic miniscrews. Am J Orthod Dentofacial Orthop. 2007;131(4 Suppl):43-51.
13. Melsen B, Verna C. Miniscrew implants: the Aarhus anchorage system. Semin Orthod. 2005;11:24-31.

14. Roze J, Babu S, Saffazadeh A, Gayet-Delacroix M, Hoomaert A, Layrolle P. Correlating implant stability to bone structure. Clin Oral Implants Res. 2009;20:1140-1145.

15. Jing Y, Han X, Guo Y, Li J, Bai D. Nonsurgical correction of a Class III malocclusion in an adult by miniscrew-assisted mandibulardentition distalization. Am J Orthod Dentofacial Orthop. 2013;143:877-887.

16. Chen K, Cao Y. Class III malocclusion treated with distalization of the mandibular dentition with miniscrew anchorage: a 2-year follow-up. Am J Orthod Dentofacial Orthop. 2015;148:1043-1053.

17. Chang C, Liu SS, Roberts WE. Primary failure rate for 1680 extra-alveolar mandibular buccal shelf mini-screws placed in movable mucosa or attached gingiva. Angle Orthod. 2015;85:905-910.

18. Chang C, Huang C, Roberts WE. 3D cortical bone anatomy of the mandibular buccal shelf: a CBCT study to define sites for extraalveolar bone screws to treat Class III malocclusion. Int J Orthod Implantol. 2016;41:74-82.

19. Elshebiny T, Palomo JM, Baumgaertel S. Anatomic assessment of the mandibular buccal shelf for miniscrew insertion in white patients. Am J Orthod Dentofacial Orthop. 2018;153:505-511.

20. Baumgaertel S. Cortical bone thickness and bone width of the posterior palatal alveolar process for mini-implant insertion in adults. Am J Orthod Dentofacial Orthop. 2011;140:806-811.

21. Kuroda S, Yamada K, Deguchi T, Hashimoto T, Kyung HM, Takano-Yamamoto T. Root proximity is a major factor for screw failure in orthodontic anchorage. Am J Orthod Dentofacial Orthop. 2007;131(4 Suppl):68-73.

22. Nucera R, Lo Giudice A, Bellocchio AM, et al. Bone and cortical bone thickness of mandibular buccal shelf for miniscrew insertion in adults. Angle Orthod. 2017;87:745-751.

23. Wilmes B, Rademacher C, Olthoff G, Drescher D. Parameters affecting primary stability of orthodontic miniimplants. J Orofac Orthop. 2006;67:162-174.

24. Baumgaertel S. Predrilling of the implant site: Is it necessary for orthodontic mini-implants? Am J Orthod Dentofacial Orthop. 2010;137:825-829.

25. Lim SA, Cha JY, Hwang CJ. Insertion torque of orthodontic miniscrews according to changes in shape, diameter and length. Angle Orthod. 2008;78:234-240. 